\title{
Underlying Management Formulas in the Sphere of Culture
}

\author{
Alexander Yakoupov \\ Russian State Specialized Academy of Arts \\ Moscow, Russia \\ E-mail:rgsai@mail.ru
}

\begin{abstract}
The paper attempts to analyze the basics of financial well-being of any art institution, considered to be based on a founder's good attitude towards its top manager, and towards an institution as a whole. However, the founder, with all his arrangements, allocates funds on the basis of certain standards, which he himself develops, and to provide additional funds for the institution headed by a manager is a great art. No matter how talented the manager is in working to create a more solid budget, he must know those norms and regulations for preparing the required documents, to accurately determine the time of budget formation, to be able to justify the production necessity to increase the budget, etc. In addition to the above, the author offers some secrets of the manager's influence on the founder's opinion.
\end{abstract}

Keywords-normative financing; enrichment; write-off of material values; intensification of production; reform; perseverance; planning; instrument of influence; responsibility; rearmament; reconstruction; overhaul; costs; prevention; "beauty treatment"; accent shift

Never earning money was easy but now it is hard even to go into bankruptcy not piling debts on debts.

Contemporary folk wisdom

\section{INTRODUCTION}

More often than not, the author was asked the question, "How did you cope with establishing a conservatory having such a solid material base in a town of regional subordination?" Yes, indeed: it has several educational buildings, utility area building (where areas were found for a printing plant, an Internet-center and seven boxes of parking house), a student campus, a garage and even an own vegetable store. The holiday village in town's vicinity (halfconstructed) included three cottages 10 rooms in each, hundreds of musical instruments, furniture and equipment.

\section{FUNDING PRINCIPLES REVIEW}

The author offers managers-beginners working in state institutions helpful tips based on the first-hand experience. Financing systems of many institutions are based on the principle "start out from the achieved", which means that funds for a next fiscal year are planned based on indexes of a current level of funds engagement in previous year. The principle is not so bad and functions in many European countries. And yet, it generates a lot of contradictions, too. Any state metropolitan university has several tens of educational buildings, dormitories, a food production building, canteens, numerous laboratories and - what is more - tens of thousands of students, who are taught and served by thousand lecturers and other workers, is not it true? Meanwhile, in provincial universities, the picture is quite different-in the best case, there are 2-3 educational buildings, not more than 3-4 laboratories, a humble canteen and several hundred lecturers. Well, what matters here is not only the less quantity of young people wishing to study at provincial higher educational institutions.

Always, such unfairness in the education system constituted a subject of discussions that were finished with a proposal to introduce the principle of normative financing, which envisaged funds allocation per one student equal for any educational institutions. Nevertheless, reasonably, the question arises: well, what then should those educational institutions do that already have a printing plant, a car fleet, construction groups, recreation bases, preventative clinics, out-patient clinics, etc. The maintenance of the above listed departments, also, finance is needed; after all they were established pursuant to directive solutions of Government. If into a norm planned per student to lay down the specified funds and introduce such norm wider to educational institutions that do not have such structures at their disposal, a budget of no country in the world, at least, of its educational sphere would withstand it. If nobody has a right to lay down such thing to the norms, the material base will fall to pieces at those, who created it during decades.

Though the financing principle "start out from the achieved" is far from perfection, and yet, it is the least evil. It has been quite approved on practice and allows ensuring financial wellbeing of any state institution. I am ready to prove it. The most optimal way of a material state improvement is annual augmenting of an institution budget a little bit higher of deflator compensating losses because of inflation.

Here are some most available ways of institution enrichment:

- Prior to the author's assignment to the position of Director of Magnitogorsk music high school, its personnel list envisaged salary a driver. There was a 
worn-down useless bus (brand "Kuban") or as it was called by punsters "Furtsvagen"1. The cost of its repair exceeded the cost of a new bus; however, that was a problem: the rigid centralized system of vehicles' distribution among institutions hogties managements.

In 1982, with the acceleration of life tempo in the country, the significance of transportation increased for development of any institution, including educational ones. The management strived finding ways of expansion and state improvement of the organization's transport fleet, but neither new salaries nor vehicles would be given to the organization by the state. According to the norm of economic activities of that time, a driver's salary could not fit to two vehicles and, on the contrary, if there was one vehicle registered in inventory, there could be no two drivers.

So, the management was forced to resort to the colleagues in the field of culture with a view to find unworkable vehicles. Consequently, a completely broken disassembled bus was found in the chapel choir that the two organizations' management agreed to pass this lumber to sign off to the music high school. For the chapel choir, this proposal was more than desirable - until the bus's signing off, they needed to wait for as long as three years (the vehicles normative operating life was considered to be 10 years.

Thus, the music high school became the owner of two buses, although, only on books. After obtaining the additional salary for driver, the second strategic stage beganremoving bus from the balance sheet. The management spent several months of tiresome bureaucratic work. Why the management was so interested in derecognizing the broken vehicle and what tricks constitute a secret of managerial science? For the Culture ministry's officials, a decisive factor was not a problem essence but the document. A manager should be ready to write tens of letters and to confirm enquiries by references. Until an issue would not be finally settled, one should keep the problem in sight. If to distract yourself for a short while, you'd need to begin everything from the up.

In the late 1990s, the conservatory's fleet included 6 new vehicles: 3 buses and 3 cars. Due to this the educational institution managed to intensify its concert activities, to accomplish reforms and to reinforce its material fundament. A good educational institution with a solid material fundament has always been the national pride. The above described experience allowed drawing the following conclusion: if a manager works systematically and persistently, he is able to resolve the most complicated problem.

- The next stage was the assistance to studentsresidents of distant regions from lower-income

The model of this "shed on wheels", intended for our industry, was made on the personal installation of the USSR Minister of Culture E.A. Furtseva. This is where the model name comes from: in a fancy way, it joins the Minister's surname and the brand of one of the best European automobile companies. families. The most important facility for them was the canteen.

Usually, an educational institution's canteen is in inventory of an outside organization, a limited liability company or an open joint-stock company, etc. There is a paradoxical situation-though an educational institution is the owner of its areas and premises, it transfers all this for lease to a private entrepreneur that, in turn, must compensate expenses on rent, utilities, etc. These expenses, as well as those concerning the transportation and cooks' work remuneration are included into the food cost, making food so expensive. The management of the conservatory managed to find an effective tool of direct influencing of the price policy in the canteen to the benefit of the students. Besides, this resulted in students' health improvement: previously, the canteen employees acquired food products of low quality and for higher price, too. Now, they had a chance to purchase products directly with rural producers under concluded contracts on meat, dairy products, cereal supplies, etc. Later the author was able to use this experience in Moscow at Central Music School and at the Russian State Specialized Academy of Arts.

A simple and yet no less effective way of this problem resolution became the method of raising personal responsibility of canteen personnel for a meal gustatory quality. The management introduced financial rewards for the canteen personnel for qualitative food and new dishes. With time, the organization got rid of irresponsive cooks. In essence, all such things form managerial details; however, they play a significant role.

The manager's main aim is to arrange the order of things in such a way that colleagues would not distract from their primary activities and spend time on resolution of difficulties not related to their direct duty.

- The universal experience of maintenance (in a proper order) of buildings and structures. Such experience depends on an institution specifics, whether it would be an educational institution or a theater, a clinic, a library, etc. Managers are aware of such a way of cardinal resolution of reparation problems as including of an institution into a large-scale state program of re-equipment, reconstruction, total overhaul. In this case, a manager has to prove that his institution serves to nationwide interests. Notwithstanding that this method realization conjugates with various difficulties (such as changeover for the reconstruction period to another building, delayed works completion, etc.), if only such possibility is open, one should make use of it. Exactly to this way, we stuck in the course of the reconstruction of the Central music school (CMS) affiliated to Moscow's conservatory. This allowed cardinally re-constructing the organization's old building, expanding educational areas more than twofold, renovating furniture and equipment, including the purchase of 18 grand pianos "Steinway \& Sons".

On practice another method had been repeatedly tested by the management, namely the method of prevention of $a$ 
dilapidation precedent consisting in regular close watch over the condition of buildings, furniture and equipment. From the psychological point of view, any, even the most insignificant destruction, has a hidden effect of a chain reaction: if accidentally a handle would be torn out from a door and the breakdown would not be repaired within one or two hours, there will be such door without handles in many places shortly after. Probably, young people feel a need in collective self-expression - in this case, a prompt attention of economic executives to liquidation of even insignificant destructions is a guarantee of a kind of property preservation in its proper form in other premises. It is respond to the events as soon as possible: at first to repair and then to raise awareness among people.

This method requires a constant attention to property safe-keeping and integrity as well as of a presence of smart specialists able to fix problems promptly. If the order of things is maintained seriously, according to the author's calculations, annually, the yearly cutdown in spending makes no less than 60 thousand dollars per 5-6 thousand sq. $\mathrm{m}$ of used areas.

- There is a great deal of other ways of improving the financial state of an institution. For example, it is quite useful to conduct a thorough calculation of expenditure on public utilities for a previous year and pay attention to a neglectful attitude of economic executives to issues of savings in heat, electricity and water consumption. (After all, it is not them, who pay; instead, the state does it). As soon as an institution would receive funds for public utilities based on its needs for previous year, from a moment of budget spending start for a new fiscal year, it is reasonable to switch on the saving lever. And for this, advisable is an installation of counting registers of heat consumption and control devices and acceptance of consumption limits - Many times, the experience proved that as for this method, within one educational year, it allowed saving up to $45-50$ thousand dollars per year.

- The practice shows that the most effective way of strengthening of an institution's material basis is the regular observance of buildings through regular annual routine repairs. In this connection, it is important to convince a founder, allocating funds for these purposes, in required volumes. As in the country, a malpractice became traditional of negligence to annual buildings routine repairs, after a lapse of 15 or 20 years of a building unmerciful operation, huge sums are required on its total overhaul. In a case of regular routine repairs, an amount designated for a total overhaul will be several times less. That is where savings are! The proceeds given for the total overhaul can be directed on current expenditure, for example, on acquisition of musical instruments.

- A no less effective method is to increase the quantity of salaries in an institution's personnel list upon the condition of beforehand-calculated increase in the payroll budget in gross. If a manager does not know the situation, a founder approves a numerical strength limit on the principle "the less, the better". If a manager would count exact number of devices requiring maintenance, the personnel list in the section "Guaranteed attending personnel" will be increased considerably. After the approval of the enlarged personnel list, the latter should be cut down to the required level; the dividends can be directed into the institution's development.

- From the financial point of view, no less effective is the method of prevention of unconscious vandalism typical to youth. When teenagers are 16 to 18 years old, they are often exposed to aggravation of the socalled finger syndrome - such are the psychological peculiarities of their age. As psychologists point out, intellect's growth is directly connected with a fingers' work. How to minimize losses? The author usually used the method in such situations called 'curing by beauty'. An effect of aesthetic finery on young people's psychic in such pragmatic way was tested for the first time during the establishment of Hall of Arts in the Magnitogorsk's Conservatory. The method offers the change of interior appearance of a small hall that before the re-decoration looked quite gloomy - instead of armchairs, there stood wooden benches on iron legs; windows were without curtains; floor was scuffed because of the benches endless movements. On a stage two shabby grand pianos with chairs stood, on which according to performers' height, seats were put tore out from other chairssuch cheerless look was common for the important premise serving the place of students' regular educational performances - academic concerts. A lot of efforts was made to turn this premise into a place really fit for concerts, without much funding.

Through the Ministry of Culture, from museums' storage, the management got pictures, small sculptures and other opuses of modern art and design related to artistic subjects. The professionals helped with the hall design project envisaging beautiful anв suitable for concerts armchairs, supports for sculptures and shop-windows for graphics, pictures and Gobelin tapestry piece, and two white concert grand-pianos on stage. Thus, the vandalism was cure with beauty.

- One more secret of management - at first sight, not concerning economics but deeply promoting it - was the method with quite a musical name Shift of Accent.

For ages officers of managerial apparatus of any educational institution contrived - in an inconceivable way to occupy dominating heights and overmaster both lecturers and students. Clerical office workers used to shout at them, workers of personnel department prescribed inconvenient time of reception and references issuing; workers of educational department required an appreciation for a given for individual studying classroom; etc. Cleaning workers and watchmen brought up both professors and students. 
One, who is able to make specialists serving to lecturers and students, is only a manager. There is only one method: a personal example. A manager himself should serve to teachers and students. If apparatus workers would feel the manager's attitude, believe me, much will be changed for the better. Nothing makes such oppressing impact on microclimate among personnel as a personality humiliation. Humiliated teachers cannot be successful in an educational process, so undertaking fades from a root. To shift the attention, focus from apparatus workers to teachers and students is a manager's strategic goal. In a creative institution, a priority should be given to creators, professors and youth!

- An effective instrument of a budget replenishment is promoting teachers' personal initiative in part of realization of major creative, scientific and pedagogical projects under federal and other targetoriented programs. Those can be contests, conferences, seminars, master-classes, etc. For a manager, it is very important to build his undertaking in such a way that such initiatives would be fulfilled not by one person but collegially. Then there is a possibility to provide the team spirit and avoid signs of the clans' formation syndrome, wide-spread at educational and creative institutions. More often than not, using a brand of an educational institution, project originators obtain a grant on its realization and then turn the undertaking to a side of selfaggrandizement or strengthening of clan-based connections in line with the formula of backscratching ("scratch my back and I will scratch yours").

A fruitful approach here can manifest itself only in one principle: by awakening initiatives, one should direct it skilfully to realization of creative interests of students and lecturers.

- The most effective way of wellbeing growth of both a personnel and an institution is assiduous economy management and well-structured management system. In the author's life journey he had occasions of meeting a great deal of creative people, actively putting their best efforts to become managers. Soon after occupying the upper-level chair, they start neglecting thrifty and economical work. In a case of an application to such a boss on the pointed-out issues, by a voice of a Celestial Father, he replies, "This is not my part of responsibility. This is what economic executives' department is occupied with; so, apply to them". Usually behind such a conduct, there is a hidden arrogance, misunderstanding of manager's role and - as the final result -inefficiency in running personnel. Most of all, a work of a head of any institution - whether it'd be an educational institution or a theater - is connected with an undelayable need of resolution of exactly domestic, economic problems.

The author's managerial activities experience for over 30 years convinces that for a settlement of creative problems in a higher educational institution or a theater, perhaps not so much time is needed as even without a rector/director, there are persons, who can resolve them. Unlike them, issues of domestic or organizational sense require a constant attention and a meticulous concern, all the more so that their settlement depends not only on internal executives but also on external ones - various firms, organizations, establishments, etc. After noticing some negligence in a refusal of a head number one to work with them, those external entities start developing a formal relation to their obligations. Yes, contacts with them take much time; however, this is a cross, which a manager is obliged to carry on with decency.

A lot of bosses can be encountered, who enjoys only with performance of representative functions; they like being a chairman, holding meetings, giving evaluations, tutoring, instructing, acting in a role of one possessing truth in the last resort, etc. Not a gaudy lot falls on a personnel headed by a manager, who sees his mission only in a role of an arbiter and tends mainly to honor dividends obtaining.

In a position of a head, a team would like to see the brightest scientists or creators; however, as a rule, the latter are not eager to be managers due to their inadaptability to such activities; - they are hardly to be torn off from their creativity, their favorite occupation. Another pair of shoes are specialists achieved their creative ceiling and having yet not satisfied their personal ambitions. Quite often, they strain after administrative running of creative higher educational institutions and artistic teams. Tending to a top of an administrative hierarchy, in their pursuit of public appreciation, they do not understand that after their appointment, their creative rating will get even lower. On one hand, it will be this way because for their personal creativity, they would not have enough of time; on the other hand, for a bulk of his subordinates, a chief is seen not as their former colleague but instead as a person having passed into the sphere of management and hence as a representative of another field of activities, of another public stratum. Even in a case that he would gain a respect, it'd be mainly for his administrative resource and managerial talent, for his deep understanding of business specifics and professional fairness in subordinates' assessment of performance. If such person was appointed to be a head, he should consider subordinates' expectations and not pretend to be a victim of a public election. A fortiori, he should not try being most talented scientist or artist at the same time - skilful decisions making on domestic issues and competent management are what people expect from him.

An experienced manager starts his working day from $a$ building walkabout. In order to see work results of housekeeping services, he, pardon, must not visit even the same lavatory. If he would choose one closest to his office room, only this one will always shine with cleanness, while other ones will remain in an improper state. Another example. If all of a sudden, a manager would need having a talk with a teacher, of course, it is possible to invite the latter to his office; what can be easier. Nevertheless, a wise head himself goes to the teacher to his classroom-by this, at the same time, he resolves several issues. Firstly, by his arrival, he shows his respect to the professor; secondly, he assesses, 
to what extent the classroom is well-groomed and clean, how it is decorated, etc.; thirdly, being in movement, he preserves his health avoiding a hypodynamia.

Also, a quite effective instrument of planning and control over execution of house-keeping and creative-pedagogical tasks are weekly briefing sessions at the director's office that usually take from a half-hour to an hour (30 minutes for educational-creative issues and other 30 minutes for housekeeping ones). Such meetings are a factor of inclusion of heads of any ranks to the management process; also, they are a factor of information uptake on activities of an institution as a whole.

The most important aspect of the manager's work is his ability to create an effective system of management of an institution. If the system functions, it means that the institution works rhythmically and there is a hope for a progress in its performance. In order that the system would be really effective, every its component is needed to be thoroughly thought over.

Usually, the main problem of creative institutions is a low level of managers' professionalism, a preparation level of which is much lower than the same of creative workers. Perhaps, this was passed down to us from the everywhere triumphant global management centralization. In due time, a management theory was studied mainly by industrial-housekeeping nomenclature, while in the humanitarian sphere, managerial techniques mastering was not practiced at all. A stake was placed on heads' selection based on the principle of finding a specialist within the organization devoted to the organization's interests. The rest employees had to rely on his professional competence.

The world science in the area of management left years away from that level. Nowadays, in many countries all around the world, a realization starts coming that a profession of a head of a creative or an educational organization is complicated and multi-facet one; it needs to be familiarized not only on practice; one needs to study theory, too. This book is not aimed at representing a management theory even in very general terms. Nevertheless, a listing would not be irrelevant of basic internal documents of an institution constituting a fundament of a systemic approach to a management. However, unfortunately, exactly paradigmatic truths are neglected by managers-beginners committing a lot of errors in their management practice.

Except for Founding Charter, about the importance of which today every manager knows gratifying to taxing authority, another necessary document regulating an inner order and workers' activities is Regulation on organization. While the Founding Charter defines legal boundaries of external production-related activities, the Regulation should describe an inner order of business-related interaction of institution members.

With purposes of management hierarchy strengthening and clarification of level of competence needed for managerial issues resolution, one more extremely important document is to be created; "Obligations distribution between rector (director) and pro-rectors (his deputies)”. Namely this document settles a scope of issues on a head at his discretion, a subordination of structural departments and extent of their competence. If a manager wants his closest assistants (deputies) working independently and responsibly, he should not only precisely outline their scope of duties but also settle a signature right on them in relation of documents belonging to their competence. This will supplement their confidence in the work; and in a case of a good microclimate in the team, it will make a figure of the deputy more significant. With purposes of responsibility increase for work conducted and control strengthening over its volume and execution deadlines complying, it is necessary to outline distinct Official duties of all categories of workers, to create own Regulation in every structural department, and to prepare other similar documents.

In a case that a manager prepared and laid open to the personnel the above listed documents, a work will be build up in a quite another way: every worker would show more responsible relation to his job and his activities in frame of the organization would be filled in with necessary content.

It is extremely important to learn how to assess subordinates work at its true worth. As the main criteria, there must be accepted professional properties of a specialist allowing adequate estimation far from judging on a personal devotion of a worker, his politeness and readiness to render a service. A professional with an intolerable temper must be appreciated higher than a nicest amateur.

A cornerstone of a management is coordinating of a management and a production process (for example, of teaching process in educational institutions), of a management and a creativity level, of a management and science, of a management and a house-keeping activities. An ideological paradigm of the management system must become justice of manager's actions in relation to his subordinates. Only then one can hope for a success. Every day, every hour and every minute, a manager is obliged worrying not only about the production but about people, too; because without their trust, it is impossible to make a noticeable progress in an undertaking, to which you serve.

Someone would ask: how to gain confidence of people?

The most effective method is working for the sake of the organization (company). For example, if institution's workers have vacations at the same time (as in a theater or in an educational institution can be), a manager is obliged giving care to people (even if he himself would be forced to stay without rest) and thoroughly preparing to the work beginning and meeting colleagues in Autumn in a renovated after a current repair building.

\section{CONCLUSION}

Summarizing it should be said that it is necessary to utilize everything that yields unfailingly some revenue of an institution, replenishes its reserve of material values and makes an institution's image nobler. It is advisable to count revenues on each source separately putting efforts to their growth from year to year. If an organization does not replenish its budget in next year, a conclusion can be made 
that its management is lazy and talentless. An indicator of a manager's inadequacy to the job is his inclination to accuse (in economic troubles of his institution) anybody or anything except for himself. Economics is an interesting area; ways of its strengthening are boundless. The author offers the strategy allowing improving it. Implementation of any innovation project in the area of economics should be thought out from the position of structure at two levels:

- The plan of stepwise actions for achievement of stated objective;

- The plan of forward-looking actions allowing actuation and stimulation of associated steps in all links of the actions stepwise plane.

In such case, a manager has a real chance to influence processes of project implementation, inspiring colleagues by his ideas and energy. In its turn, a group of responsible officials should concentrate attention on realization of the plan of stepwise actions.

Concerning to a manager's personal memory card, budget is not a final sentence since there are many forms of its replenishment. For example: 1) commercial activities of the institution (supremely promising sphere); 2) private donations; 3) sponsors' deposits; 4) profitable contracts (orders), etc.

\section{REFERENCES}

[1] Kim S. Cameron, Robert E. Quinn, Diagnosing and Changing Organizational Culture, Addison-Wesley, 2001.

[2] H. Mintzberg, B. Ahlstrand, J. Lampel, Strategy Safari, Prentice Hall, 2001.

[3] H. Mintzberg, Structure in Five, Prentice/Hall International, Inc., 2002.

[4] A.T. Zub, Strategic Management. Theory and Practice. Aspect Press, M., 2002.

[5] E.M. Korotkov, Administrating the Quality of Education. M., 2007. 